\title{
Initiation of Enzyme Replacement Therapy for an Adult Patient with Asymptomatic Type 1 Gaucher's Disease
}

\author{
Naoki TAnAKA ${ }^{*, * *}$, Hiroshi SaIto*, Toshiro Ito*, Kayoko Momose*,**, Fumihiro IshidA ${ }^{*, * *}$, \\ Kazuhiko HorA**, Kendo KIYosawA** and Hiroyuki IDA***
}

\begin{abstract}
A 27-year-old woman was admitted for further examination of thrombocytopenia. Symptoms were absent, but physical examination demonstrated hepatosplenomegaly without neurological abnormalities. Bone marrow examination revealed many Gaucher cells, and glucocerebrosidase activity from cultured skin fibroblasts was markedly reduced. A 1448C (L444P) mutation was detected on one allele of the glucocerebrosidase gene. Because magnetic resonance imaging (MRI) of the femora indicated severe infiltration of Gaucher cells into bone marrow, enzyme replacement therapy was initiated despite the absence of skeletal symptoms. Hematologic abnormalities, visceral and bone involvement have been improving. In cases of thrombocytopenia or hepatosplenomegaly, Gaucher's disease should be suspected.
\end{abstract}

(Internal Medicine 40: 716-721, 2001)

Key words: $1448 \mathrm{C}$ (L444P) mutation, bone involvement, MRI, enzyme replacement therapy

\section{Introduction}

Gaucher's disease is the most common lysosomal disorder caused by a deficiency of glucocerebrosidase (acid $\beta$-glucosidase) (1). Because this enzyme degrades glucocerebroside, a component of cell membranes, its deficiency results in abnormal accumulation of glucocerebroside in the reticuloendothelial system and causes hepatosplenomegaly and skeletal involvement (2). Gaucher's disease is inherited in an autosomal recessive manner and caused by various mutations of the glucocerebrosidase gene, which is located on chromosome 1q21 (3). More than 60 mutations have been identified to date $(4,5)$. This disease is classified into three clinical forms: type 1 (nonneuronopathic type), type 2 (acute neuronopathic type), and type 3 (subacute neuronopathic type). Type 1 Gaucher's disease, the most common in Japan, is markedly heterogeneous in clinical features and glucocerebrosidase gene mutations (2, 6). Recently, it has been reported that enzyme replacement therapy for type 1 Gaucher's disease may improve hematologic abnormalities as well as visceral and bone involvement (7-9). We present an uncommon adult case diagnosed as type 1 Gaucher's disease and treated with enzyme replacement therapy.

\section{Case Report}

A 27-year-old woman was admitted to our hospital for further examination of thrombocytopenia. She had been in good health and nothing abnormal had been found at a routine checkup. One month before admission, she felt lower abdominal discomfort and went to another hospital, where her blood was examined. Abdominal discomfort improved spontaneously but the blood examination indicated a reduced platelet count $\left(5.9 \times 10^{4} / \mathrm{mm}^{3}\right)$, and she was referred to our hospital in June 1997. There were no symptoms of fever, bone pain, abdominal fullness, purpura or hypermenorrhea. She had not received any blood transfusions, nor used any alcohol or habitual drugs. There were no hematologic or neurological disorders in her family history, but there was a consanguineous marriage in the paternal family (Fig. 1).

On admission, her height was $165 \mathrm{~cm}$, her weight $60 \mathrm{~kg}$, her temperature $37.0^{\circ} \mathrm{C}$, her pulse rate $80 / \mathrm{min}$ and her blood pressure $120 / 72 \mathrm{mmHg}$. Physical examination revealed a nontender liver edge $5 \mathrm{~cm}$ below the right costal margin and a spleen edge $6 \mathrm{~cm}$ below the left costal margin. The liver had a smooth surface and a dull edge, and was elastically firm. No purpura, gum bleeding, lymphadenopathy, bone deformity or tenderness was noted. Neurological examination results were normal. No abnormal eye movement, including horizontal supranuclear gaze palsy or ocular motor apraxia, mental retardation or hearing disability was observed.

Laboratory data on admission showed mild anemia $(\mathrm{Hb}, 9.5$

From *the Department of Internal Medicine, Nagano Red Cross Hospital, Nagano, **the Second Department of Internal Medicine, Shinshu University School of Medicine, Matsumoto and ***the Department of Pediatrics, Jikei University School of Medicine, Tokyo

Received for publication May 23, 2000; Accepted for publication March 30, 2001

Reprint requests should be addressed to Dr. Naoki Tanaka, the Second Department of Internal Medicine, Shinshu University School of Medicine, 3-1-1 Asahi, Matsumoto 390-8621 


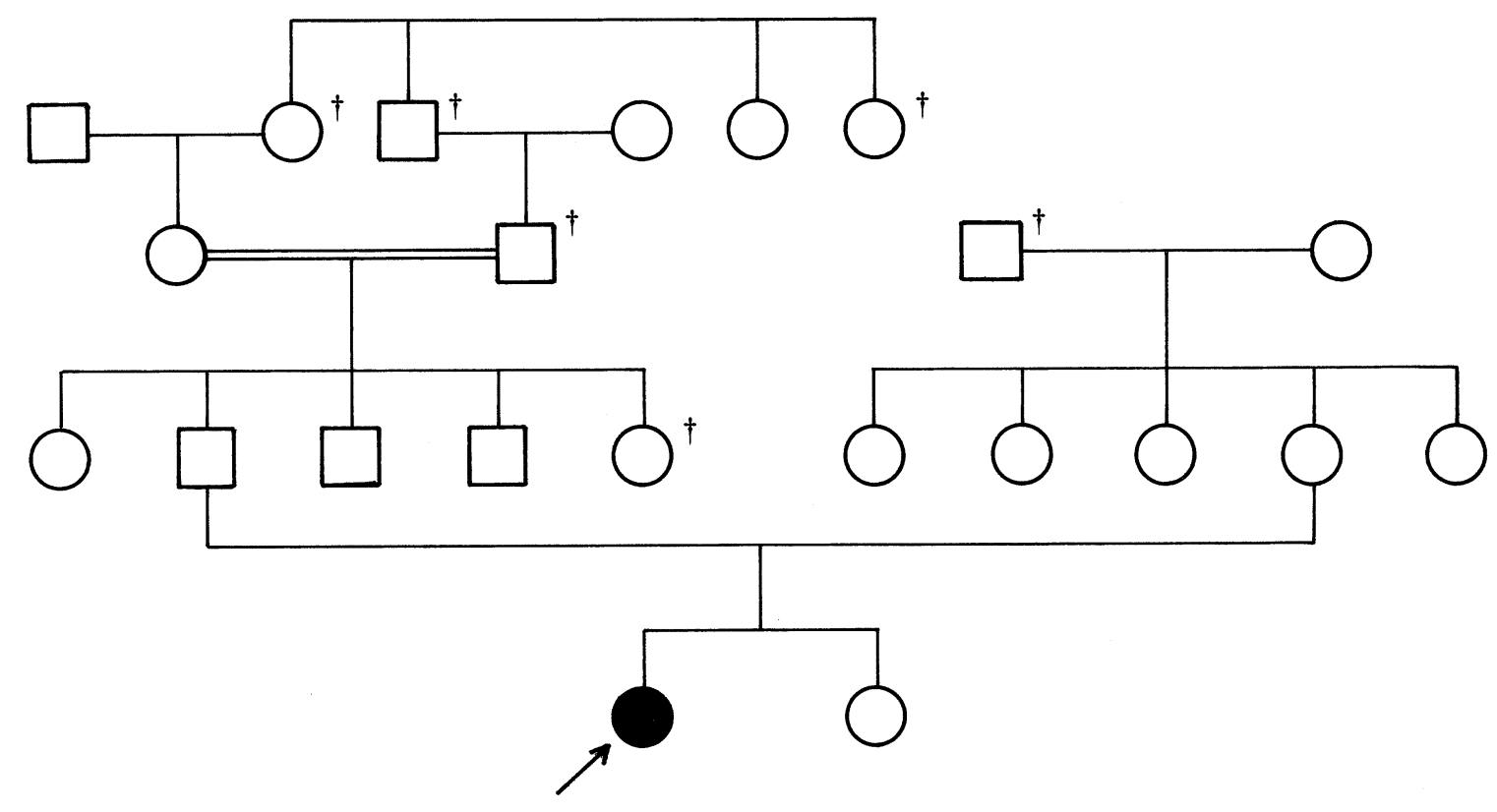

Figure 1. Pedigree of the patient's family. Arrow indicates the present patient.

$\mathrm{g} / \mathrm{dl}$; normal, 11.1-15.1), thrombocytopenia $\left(6.0 \times 10^{4} / \mathrm{mm}^{3}\right.$; normal, 13.0-35.0 $\left.\times 10^{4}\right)$ and elevated levels of acid phosphatase (39.5 IU/l; normal, 3.5-14.4) and angiotensin-converting enzyme (56.5 IU/l; normal, 8.3-21.4). However, the levels of asparate aminotransferase (24 IU/l; normal, 12-37) and alanine aminotransferase (17 IU/l; normal, 7-45) were normal. Chest X-ray and electrocardiogram were normal, but abdominal X-ray revealed moderate hepatosplenomegaly. Abdominal computed tomography (CT) scan obtained at admission (Fig. 2A) also showed hepatosplenomegaly without swelling of lymph nodes, ascites or abnormal mass. Bone marrow aspiration for further investigation of thrombocytopenia and hepatosplenomegaly demonstrated the presence of many histiocytes with a wrinkled tissue paper appearance (Fig. 3), which is characteristic of Gaucher cells. The histiocytes were positive for both periodic acid Schiff and acid phosphatase staining. Measurement of glucocerebrosidase activity in cultured skin fibroblasts, using 4-methylumbelliferyl- $\beta$-D-glucoside as substrate (6), revealed a significant decrease to $7 \%$ compared with normal control $[3.7 \mathrm{nmol} / \mathrm{mg}$ protein/hour; normal, $53 \pm 10$ $(\mathrm{n}=3$, mean $\pm \mathrm{SD})]$.

Differentiation between type 1 and type 3 Gaucher's disease, especially the type $3 \mathrm{~b}$ variant, is sometimes difficult because neurological manifestations in type 3 appear later in life. However, neurological symptoms and signs, including horizontal supranuclear gaze palsy, which is the only neurological manifestation of the type $3 \mathrm{~b}$ variant (10), were not observed at the time of diagnosis. Moreover, no abnormalities were seen on electroencephalogram, brain magnetic resonance imaging (MRI) scan or auditory brainstem response. Therefore, a diagnosis of type 1 Gaucher's disease was made.
After the patient's informed consent had been obtained, analysis of the glucocerebrosidase gene on genomic DNA extracted from her peripheral blood leukocytes was performed as previously reported $(6,11,12)$. To identify seven common mutations, i.e. 1448C (L444P), 754A (F213I), 1342C (D409H), 1504T (R463C), IVS2+1, 84GG and 1226G (N370S), polymerase chain reaction (PCR) of genomic DNA was carried out using specific primers, and PCR products were digested with appropriate restriction enzymes $(6,11,12)$. Digestion with $N c i$ I confirmed the presence of the $1448 \mathrm{C}$ mutation in one allele (Fig. 4). In another allele, however, none of the seven common mutations could be identified with this method. Moreover, polymerase chain reaction-single-strand conformation polymorphism (PCR-SSCP) analysis of exons 2 to 11 of the glucocerebrosidase gene (6) could not detect any mutations. Analysis of the $1448 \mathrm{C}$ mutation on the patient's parents' genomic DNA was also performed with the same method, after their informed consent had been obtained. The presence of this mutation was confirmed in one allele of the maternal glucocerebrosidase gene, but not the paternal one (Fig. 4).

The patient had a younger sister without any complaints or any symptoms. Since her physical examination and laboratory data revealed no abnormalities, no genetic analysis was performed.

Although the patient had not complained of any skeletal symptoms, MRI scan of marrow of the femora showed a reduced intensity on the T1-weighted image (T1WI) and a heterogeneous intensity on the T2-weighted image (T2WI), but without avascular necrosis (Fig. 5A), indicating severe infiltration of Gaucher cells into marrow. Considering that it has been reported that the $1448 \mathrm{C}$ mutation is linked to a severe and 

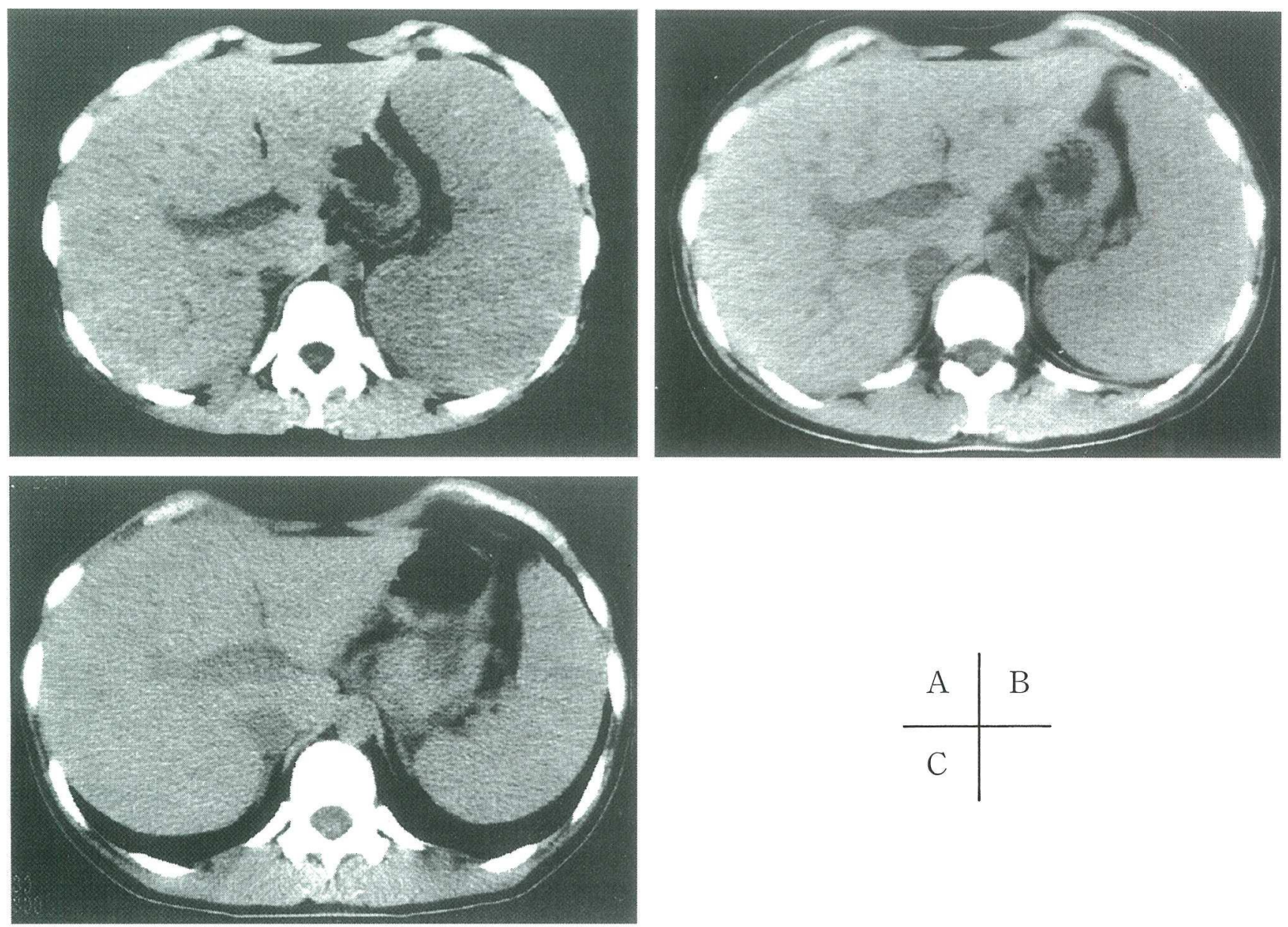

Figure 2. Abdominal CT scan without contrast enhancement. A) On admission. Moderate hepatosplenomegaly is observed. B) At six months after the start of enzyme replacement therapy, splenomegaly gradually improved. C) After 24 months of treatment, the size of liver and spleen became normal.

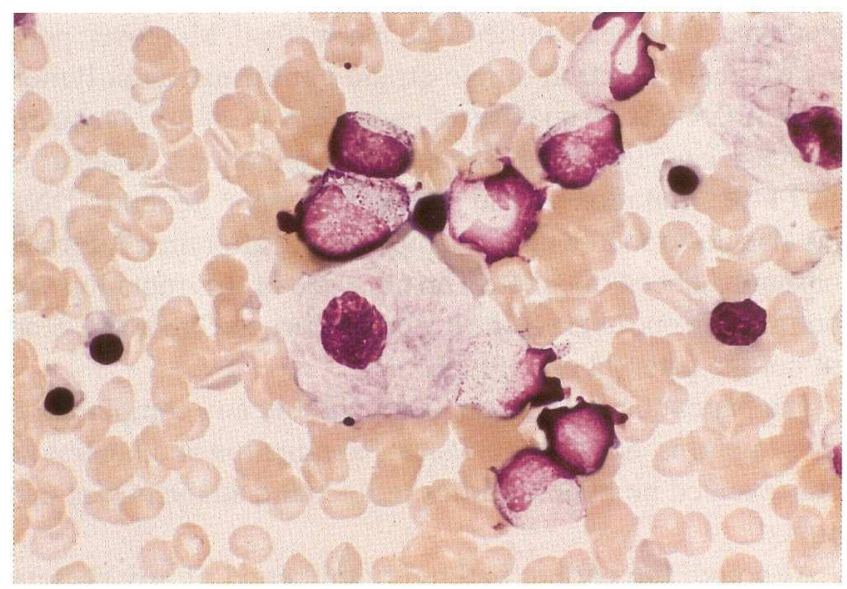

Figure 3. Bone marrow examination shows large histiocytes with a wrinkled tissue paper appearance. Wright-Giemsa staining, $\times 400$.

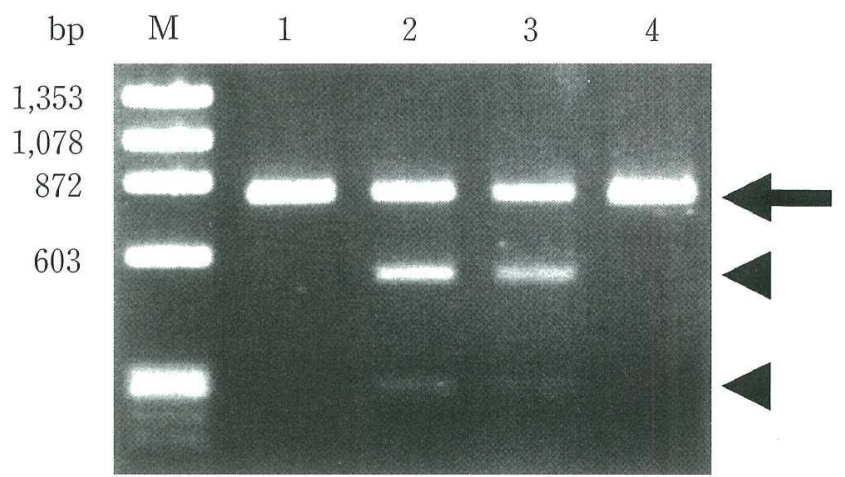

Figure 4. Detection of the $1448 \mathrm{C}$ mutation on the glucocerebrosidase gene. Exons 9 to 11 of glucocerebrosidase gene were amplified by polymerase chain reaction (PCR). The normal PCR product was not digested with $N c i$ ( $825 \mathrm{bp}$, arrow), whereas the $\mathrm{PCR}$ product with the $1448 \mathrm{C}$ mutation was cleaved into a 525 and a 300 bp fragment (arrowheads). M: DNA molecular weight marker, 1: the patient's father, 2: the patient's mother, 3: the patient, 4: control. 


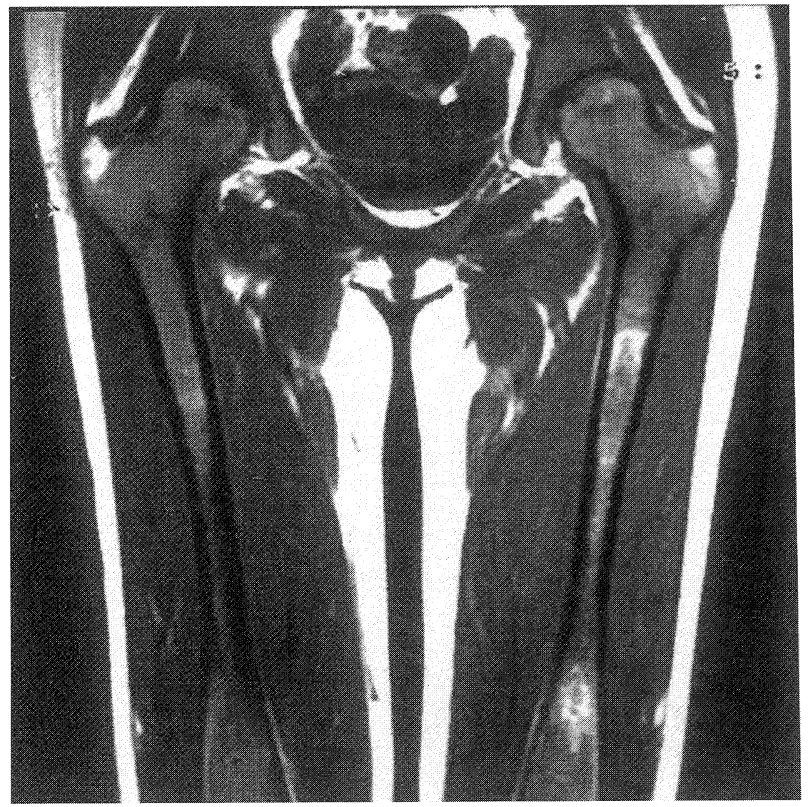

T1WI

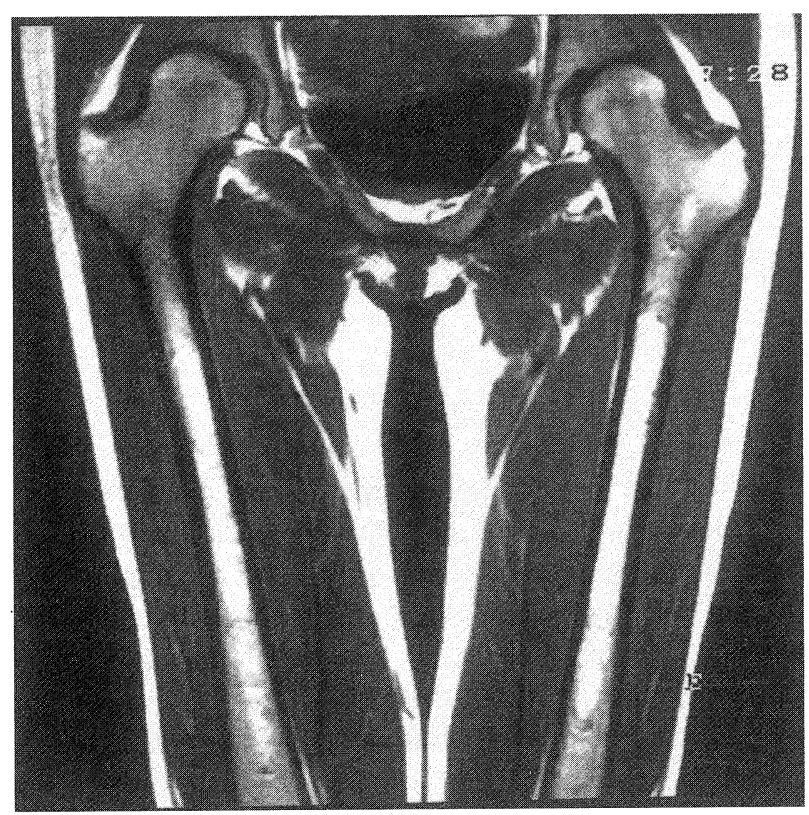

T1WI

$\mathrm{B}$

progressive phenotype (13) and that bone involvement was found to be severe, we recommended enzyme replacement therapy to her and her family. After obtaining their consent, a mannose-terminated placenta-derived glucocerebrosidase alglucerase $\left(\right.$ Ceredase $^{\circledR}$, Genzyme Corporation, Boston, MA ; 60 units per kilogram of body weight) was administered intravenously every two weeks; it was later replaced with a recom-

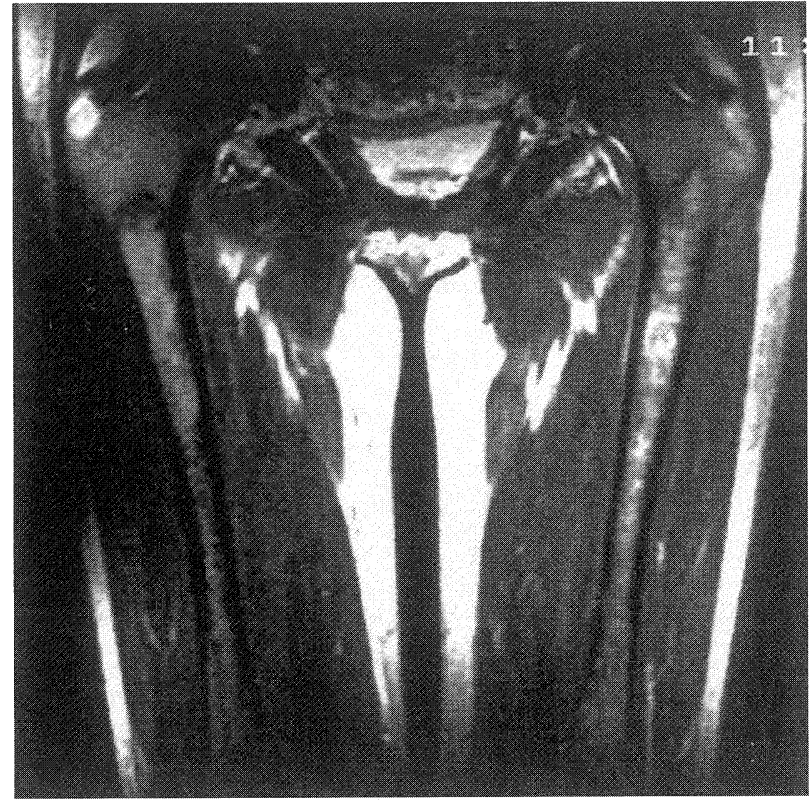

T2WI
A

Figure 5. Coronal MRI scan of the entire femora. A) On T1weighted image (T1WI) obtained at admission, bone marrow appears hypointense, demonstrating that the marrow fat content has decreased due to the displacement of triglyceride-rich adipocytes by Gaucher cells. T2-weighted image (T2WI) shows a heterogeneous intensity. Avascular necrosis is not seen. B) On T1WI after 24 months of treatment, marrow signal intensity has increased compared with that before initiation of treatment, indicating improvement in marrow composition due to a marked reduction in Gaucher cells.

binant enzyme imiglucerase (Cerezyme ${ }^{\circledR}$, Genzyme Corporation). After 6 months of enzyme replacement therapy, the hemoglobin and platelet count had returned to normal and splenomegaly gradually improved (Figs. 2B and 6), but bone involvement remained unchanged (data not shown). After 24 months of treatment, the size of liver and spleen had become normal and the intensity on T1WI of the MRI scan of the femora 


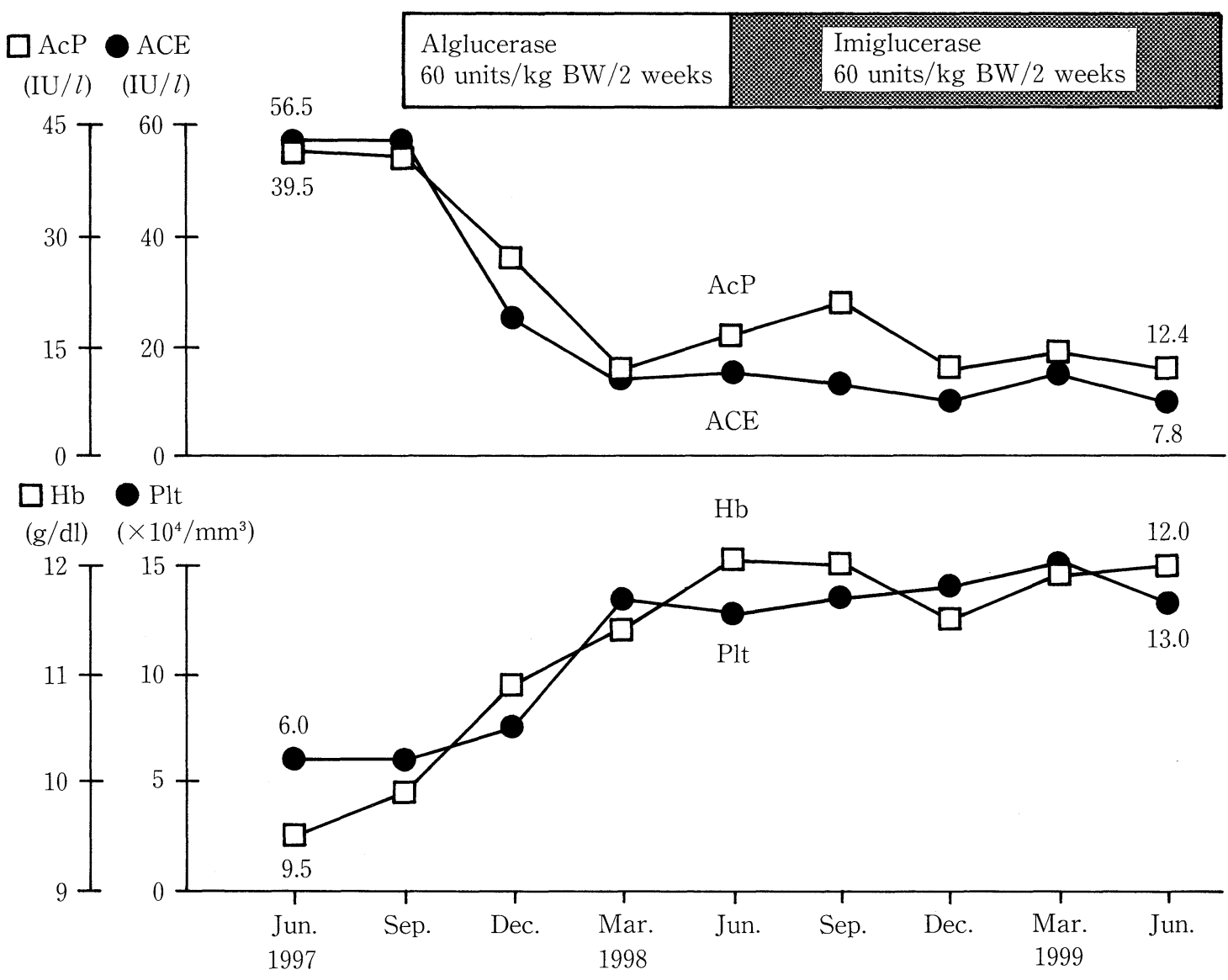

Figure 6. Clinical course as evidenced by laboratory findings. ACE: angiotensin-converting enzyme, AcP: acid phosphatase, BW: body weight, Hb: hemoglobin, Plt: platelet.

showed gradual improvement (Fig. 5B). The patient has continued this treatment without adverse effect and has remained in good health.

\section{Discussion}

Gaucher's disease is the most prevalent lysosomal disorder in Japan and about fifty patients with this disease are alive now. The present case is unique because the patient showed late onset and no symptoms. The mean age at the diagnosis of Japanese type 1 Gaucher patients is 8 years and less than $15 \%$ of all patients are diagnosed at more than 25 years of age (14). Moreover, most Japanese Gaucher patients have certain symptoms or signs, including abdominal distention, hepatosplenomegaly and bone pain, at the time of diagnosis, and tend to show more severe and progressive clinical features than non-Japanese patients $(14,15)$. The present case supports the concept that type 1 Gaucher's disease is highly heterogeneous in its clinical features, i.e. age of onset, severity and progression. In cases with thrombocytopenia or hepatosplenomegaly, therefore, even in adults, Gaucher's disease should be suspected.

In type 1 Gaucher's disease, bone involvement is clinically significant. Accumulation of glucocerebroside in bone marrow leads to bone loss, failure to remodel and avascular necrosis (2). More than half of the patients with Japanese type 1 Gaucher's disease suffer from serious bone complications including bone crisis, pathologic fracture of long bones or compression fracture of the spine, which sometimes seriously impair the quality of life of the patients (15). For evaluation of bone involvement, MRI scan is the most sensitive and useful procedure $(9,16)$. Terk et al proposed a system for staging marrow and bone changes on MRI scans in proportion to their clinical severity (17). In our patient, severe bone involvement was detected by MRI scan of the entire femora in spite of the absence of skeletal symptoms or signs, and this finding led to the decision to initiate enzyme replacement therapy. Therefore, MRI scan of the entire femora is indispensable for determining the indication for enzyme replacement therapy.

Some correlation between genotypes and phenotypes has been reported $(2,13,18)$. For example, the $1226 \mathrm{G}$ mutation (a $\mathrm{G}$ to $\mathrm{A}$ transition at nucleotide 5841, leading to the substitution of serine for aspargine at residue 370), which is common in Jewish but absent in Japanese patients (12), tends to be linked to a very mild phenotype $(13,18)$. Nearly $90 \%$ of the patients 
homozygous for $1226 \mathrm{G}$ have a very mild clinical course or are sometimes asymptomatic, so that this mutation is known as a "protective mutation" $(4,13,18)$. On the other hand, the $1448 \mathrm{C}$ mutation (a $\mathrm{T}$ to $\mathrm{C}$ transition at nucleotide 6433 , leading to the substitution of proline for leucine at residue 444), which has been detected in more than $40 \%$ of Japanese Gaucher patients (6), is associated with severe and progressive clinical features. This mutation encodes an unstable glucocerebrosidase with low catalytic activity (19) and has been frequently identified in patients with a neuronopathic form (20) or an early-onset and severe nonneuronopathic form of Gaucher's disease (13). Genetic analysis of our patient showed $1448 \mathrm{C} /$ ? (unidentified) genotype in spite of the absence of any symptoms, leading us to speculate that the unidentified allele is protective against the 1448C allele. PCR-SSCP analysis is recognized as a simple and rapid technique for screening of common mutations (6), but we could not identify an abnormal allele with this method. If PCR-SSCP fails to detect a mutation, denaturing gradient gel electrophoresis may be needed as a more sensitive and informative screening method (21). Ultimately, sequencing of the entire glucocerebrosidase gene will be necessary for the detection of the unknown mutation.

Because of the great clinical heterogeneity of type 1 Gaucher's disease and the high cost of enzyme replacement therapy, the indication for this treatment is problematic. Although the present patient had not complained of any symptoms, we immediately initiated full-dose enzyme replacement therapy for the following reasons: (i) in general, Japanese type 1 Gaucher's disease tends to be severe and progressive (14, 15); (ii) the MRI scan of the entire femora suggested that serious bone complications including pathological fracture or avascular necrosis might occur later; (iii) the skeletal response to enzyme replacement therapy is much slower than the visceral or hematologic response (Figs. 2, 5 and 6), and once serious bone complications occur, the effect of enzyme replacement therapy on bone lesions may be limited $(9,22)$; and (iv) insufficient enzyme replacement (15-30 units per kilogram of body weight every two weeks) cannot prevent the progression of severe bone involvement (15). We therefore decided that, to prevent serious skeletal complications and the accompanying impairment of quality of life, our patient should be treated with long-term and full-dose enzyme replacement therapy. In addition, long-term follow-up and careful physical examination will be needed because the possibility of a mild case of type 3 Gaucher's disease cannot be completely excluded.

\section{References}

1) Brady RO, Kanifer JN, Shapiro D. Metabolism of glucocerebrosides. II. Evidence of an enzymatic deficiency in Gaucher's disease. Biochem Biophys Res Commun 18: 221-225, 1965.
2) Beutler E, Grabowski G. Gaucher diease. in: The Metabolic Basis of Inherited Disease. 7th ed. Scriver CR, Beaudet AL, Sly WS, Valle D, Eds. McGraw-Hill, New York, 1995: 2641-2670.

3) Ginns EI, Choudary PV, Tsuji S, et al. Gene mapping and leader polypeptide sequence of human glucocerebrosidase: implications for Gaucher disease. Proc Natl Acad Sci USA 82: 7101-7105, 1985.

4) Horowitz M, Zimran A. Mutations causing Gaucher disease. Hum Mutat 3: 1-11, 1994.

5) Beutler E, Gelbart T. Glucocerebrosidase (Gaucher disease). Hum Mutat 8: 207-213, 1996.

6) Ida H, Rennert OM, Kawame H, Maekawa K, Eto Y. Mutation prevalence among 47 unrelated Japanese patients with Gaucher disease: identification of four novel mutations. J Inherit Metab Dis 20: 67-73, 1997.

7) Beutler E, Kay A, Saven A, et al. Enzyme replacement therapy for Gaucher disease. Blood 78: 1183-1189, 1991.

8) Rosenthal DI, Doppelt SH, Mankin HJ, et al. Enzyme replacement therapy for Gaucher disease: skeletal responses to macrophage-targeted glucocerebrosidase. Pediatrics 96: 629-637, 1995.

9) Charrow J, Esplin JA, Gribble TJ, et al. Gaucher disease: recommendations on diagnosis, evaluation, and monitoring. Arch Intern Med 158: 1754-1760, 1998.

10) Patterson MC, Horowitz M, Abel RB, et al. Isolated horizontal supranuclear gaze palsy as a marker of severe systemic involvement in Gaucher's disease. Neurology 43: 1993-1997, 1993.

11) Beutler E. Gaucher disease: new molecular approaches to diagnosis and treatment. Science 256: 794-799, 1992.

12) Ida $H$, Iwasawa $K$, Kawame $H$, Rennert OM, Maekawa $K$, Eto Y. Characteristics of gene mutations among 32 unrelated Japanese Gaucher disease patients: absence of the common Jewish 84GG and $1226 \mathrm{G}$ mutations. Hum Genet 95: 717-720, 1995.

13) Zimran A, Sorge J, Gross E, Kubitz M, West C, Beutler E. Prediction of severity of Gaucher's disease by identification of mutations at DNA level. Lancet 2: 349-352, 1989.

14) Ida H, Rennert OM, Ito T, Maekawa K, Eto Y. Type 1 Gaucher disease: phenotypic expression and natural history in Japanese patients. Blood Cell Mol Dis 24: 73-81, 1998.

15) Ida H, Rennert OM, Kato $S$, et al. Severe skeletal complications in Japanese patients with type 1 Gaucher disease. J Inherit Metab Dis 22: 63-73, 1999.

16) Rosenthal DI, Scott JA, Barranger J, et al. Evaluation of Gaucher disease using magnetic resonance imaging. J Bone Joint Surg [Am] 68: 802-808, 1986.

17) Terk MR, Esplin J, Lee K, Magre G, Colletti PM. MR imaging of patients with type 1 Gaucher's disease: relationship between bone and visceral changes. Am J Roentgenol 165: 599-604, 1995.

18) Sibille A, Eng CM, Kim SJ, Pastores G, Grabowski GA. Phenotype/genotype correlations in Gaucher disease type I: clinical and therapeutic implications. Am J Hum Genet 52: 1094-1101, 1993.

19) Grace ME, Newman KM, Scheinker V, Berg-Fussman A, Grabowski GA. Analysis of human acid $\beta$-glucosidase by site-directed mutagenesis and heterologous expression. J Biol Chem 269: 2283-2291, 1994.

20) Tsuji S, Choudary PV, Martin BM, et al. A mutation in the human glucocerebrosidase gene in neuronopathic Gaucher's disease. N Engl J Med 316: 570-575, 1987.

21) Theophilus BD, Latham T, Grabowski GA, Smith FI. Comparison of RNase A, a chemical cleavage and GC-clamped denaturing gradient gel electrophoresis for the detection of mutations in exon 9 of the human acid $\beta$-glucosidase gene. Nucleic Acids Res 17: 7707-7722, 1989.

22) Hermann G, Pastores GM, Abdelwahab IF, Lorberboym AM. Gaucher disease: assessment of skeletal involvement and therapeutic responses to enzyme replacement. Skeletal Radiol 26: 687-696, 1997. 